\title{
Prevalence and Risk factors for Urinary Incontinence in postmenopausal women
}

\author{
Authors \\ Prajakta Deshmukh $^{1^{*}}$, Dr Nitin Nikhade $(\mathrm{PT})^{2}$, Dr Snehal Ghodey $(\mathrm{PT})^{3}$ \\ ${ }^{1}$ BPTH Intern MAEER'S Physiotherapy College, Talegaon Dabhade \\ ${ }^{2}$ Professor MAEER'S Physiotherapy College, Talegaon Dabhade \\ ${ }^{3}$ Principal, MAEER'S Physiotherapy College, Talegaon Dabhade \\ Corresponding Author \\ Prajakta Deshmukh \\ BPTH Intern MAEER’S Physiotherapy College, Talegaon Dabhade
}

\begin{abstract}
Urinary incontinence is the involuntary loss of urine which is objectively demonstrable and is social and hygienic problem. The prevalence of urinary incontinence has been reported to increase at menopause and menopausal age.

Aim: To find out the prevalence of urinary incontinence and risk factors among postmenopausal women. Subjects and Method: 105 subjects were selected in the age group of 45-65 based on inclusion and exclusion criteria in and around Talegaon Dabhade. Questionnaire of female urinary incontinence diagnosis was asked by the therapist to the subjects.

Results: The prevalence of urinary incontinence was found to be 55\% among postmenopausal women. Mixed urinary incontinence was the commonest type.

Conclusion: The study shows the prevalence of urinary incontinence was $55 \%$ among postmenopausal women in Talegaon Dabhade. Parity 3 or more, Increasing age, Hysterectomy, Diabetes mellitus and high BMI were the risk factors associated with it.
\end{abstract}

Keywords: Urinary Incontinence, Postmenopausal Women.

\section{Introduction}

Urinary incontinence is the involuntary loss of urine which is objectively demonstrable and is social and hygienic problem ${ }^{1}$. The prevalence of urinary incontinence has been reported to increase at menopause and menopausal age and is more common in women than in men implicating menopause $^{2}$. Common types of urinary incontinence are Stress, Urge, Extraurethral, Giggle, Overflow, Reflex, Nocturnal enuresis, Orgasmic ${ }^{1}$.

Stress urinary incontinence is characterized by involuntary leakage on effort or exertion, or sneezing, or coughing ${ }^{1}$. Urge urinary incontinence includes accidental urine loss that accompanied by or proceed by feeling of urgency ${ }^{1}$. Risk factors for urinary incontinence in women includes Pregnancy, Vaginal birth, Obesity, Family history, Increasing age, Lower urinary tract symptoms, Disability such as Dementia or Multiple Slerosis ${ }^{3}$.

Urinary incontinence affects quality of life in women. It also affects a women's physical wellbeing and it also has impact on socioeconomic and psychological aspects of women's life ${ }^{4}$.

The prevalence of urinary incontinence is estimated to be $12-69 \%$, although estimates vary greatly in 
different countries and depends upon the age of study group ${ }^{4}$. Fred kriss et al. found prevalence of $18.12 \%$ in Estonian postmenopausal women. ${ }^{5}$ Uma singh et al. found prevalence of $21.87 \%$ in Indian women. ${ }^{6}$ Senturk et al. found prevalence of $45.6 \%$ in postmenopausal women living in Turkey ${ }^{7}$. There are few studies done in India on prevalence and risk factors of urinary incontinence in postmenopausal women. The aim of this study was to estimate the prevalence and risk factors of urinary incontinence in postmenopausal women.

Medical management focuses on treating urinary tract infection following urinary incontinence. Kegal's exercises and life style modification are the physiotherapeutic management for urinary incontinence.

\section{Methodology}

The following is a cross sectional study carried out by simple random sampling. The study was conducted on postmenopausal women between the age group of 45-65 and one year post hysterectomy women. Subjects with neurological bladder problems, urinary tract infection, cognitive problems, and immediate post hysterectomy incontinence were excluded. Questionnaire for female urinary incontinence diagnosis was used. ${ }^{16}$

\section{Procedure}

Subject's informed consent was taken. 105 subjects were selected on the basis of inclusion an exclusion criteria and demographic data such as age, height, weight, BMI, parity smoking history, diabetes mellitus, etc. was taken from the subjects. Questionnaire of Female urinary incontinence diagnosis was asked by the therapist in the form of interview in local language of the subjects and filling of the form was done by the therapist. The Questionnaire includes questions about urinary incontinence. In that first three questions are for stress urinary incontinence and other three are for urge urinary incontinence. If the subjects have both the symptoms then it is considered as mixed urinary incontinence.

\section{Data Analysis and Results}

Graph 1: Prevalence of urinary incontinence in postmenopausal

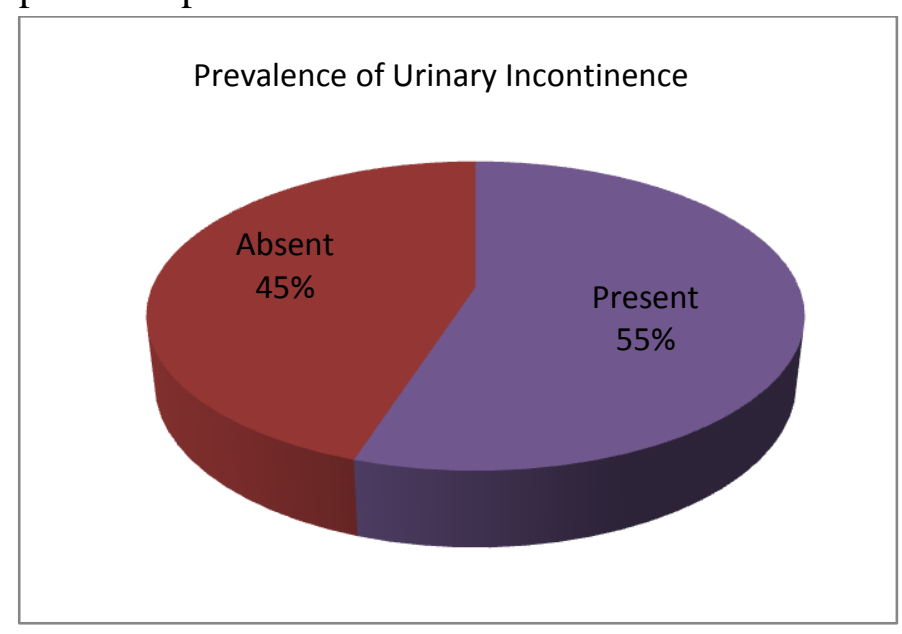

Graph 2: Distribution of subjects as per types of urinary incontinence in postmenopausal women

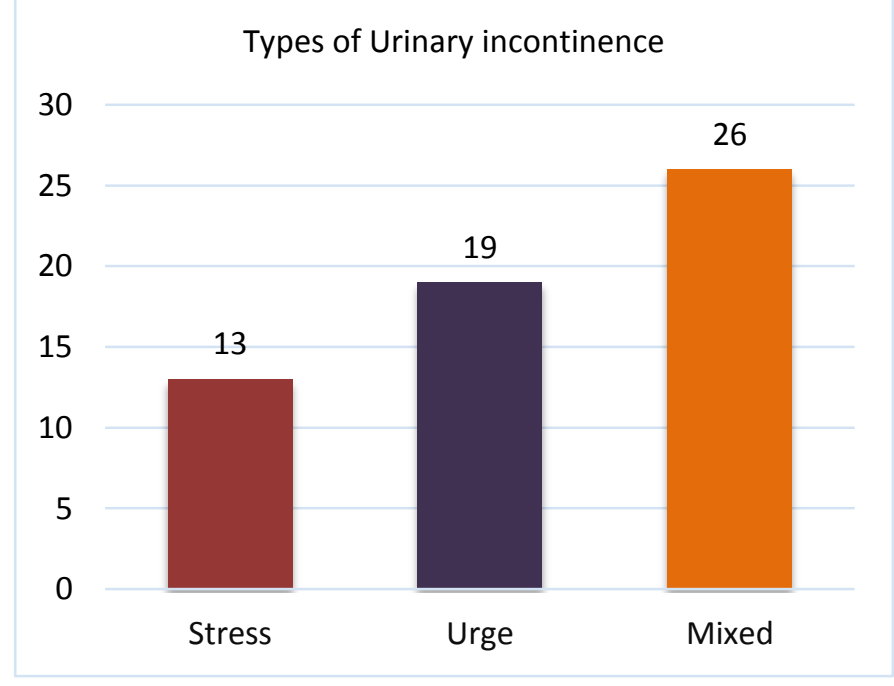

Graph 3: Age wise distribution of subjects having urinary incontinence in postmenopausal women

COMPARISON BETWEEN AGE GROUP AND UI

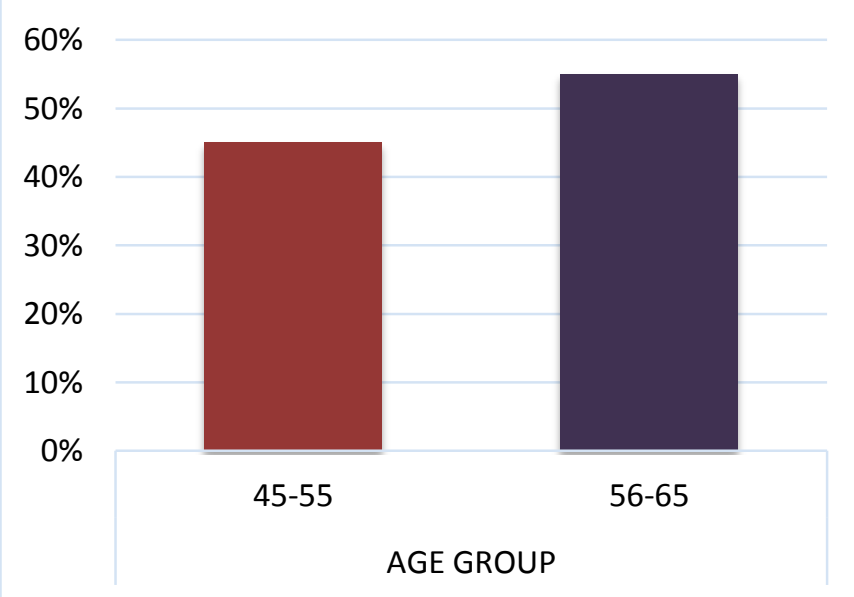




\section{JMSCR Vol||07||Issue||07||Page 695-699||July}

Graph 4: Percentage of urinary incontinence cases according to parity

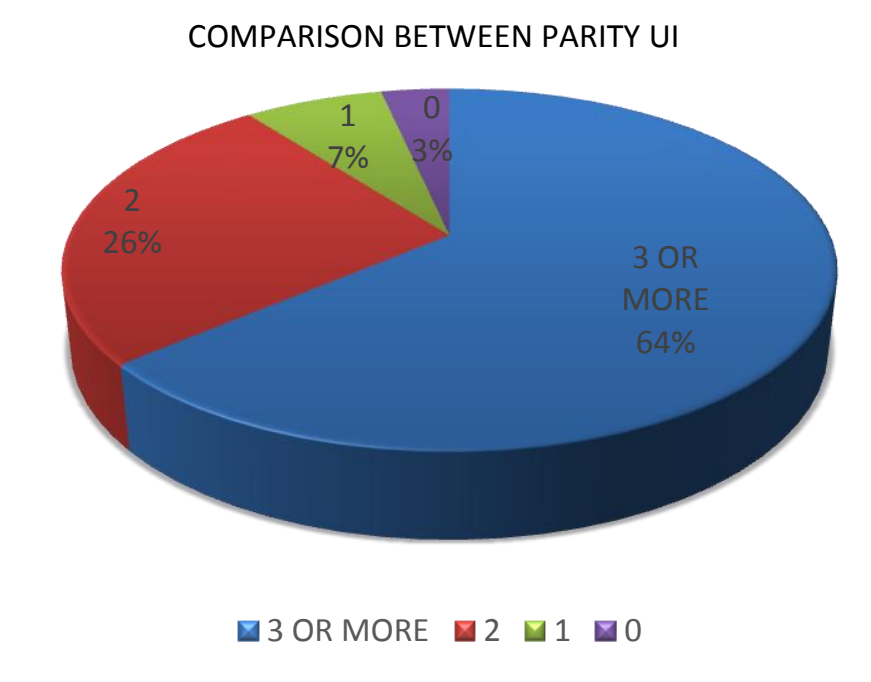

Graph 5: Distribution of urinary incontinence cases in diabetes and normal individual

UI NON UI

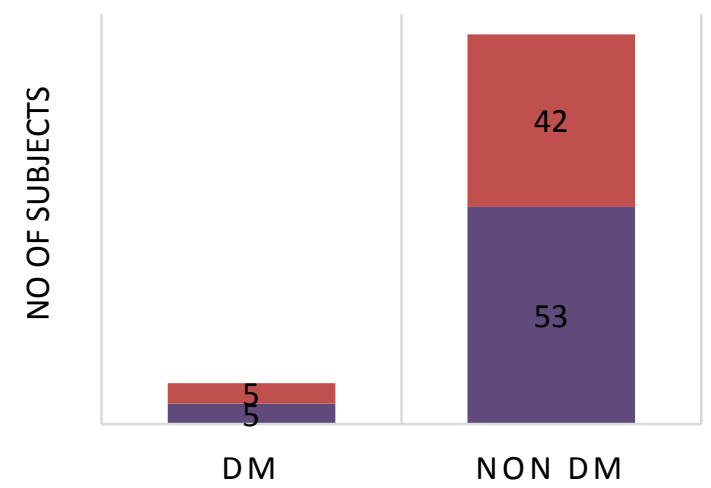

Graph 6: Distribution of urinary incontinence in women with hysterectomy

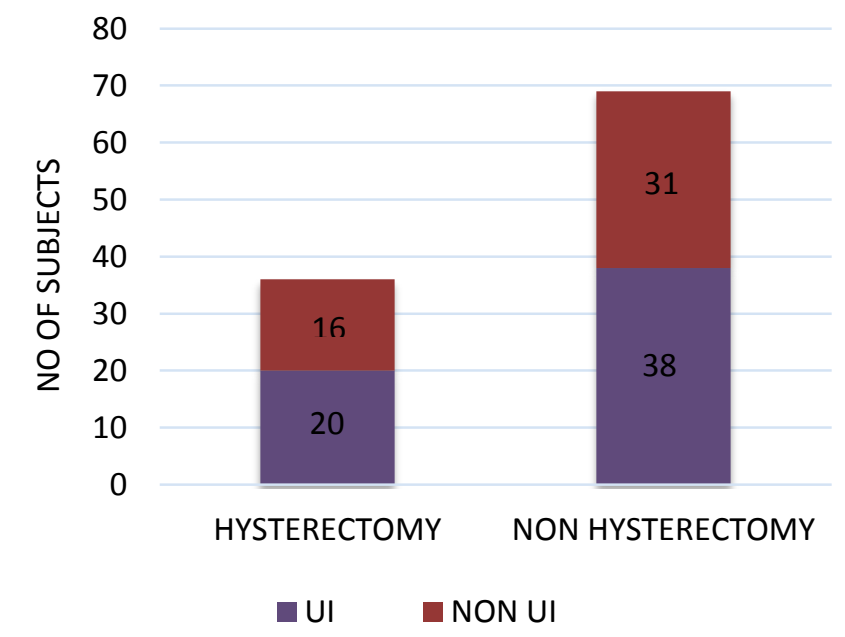

Graph 7: Percentage of urinary incontinence cases according

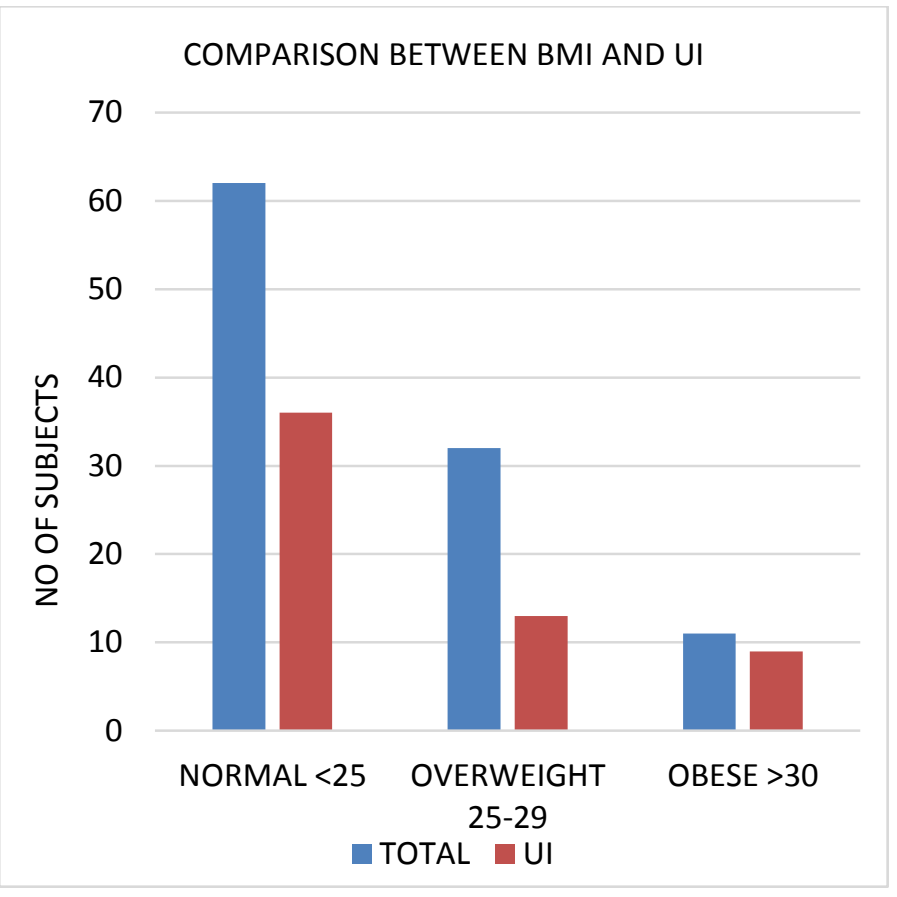

\section{Discussion}

This study was done to find out the prevalence and risk factors of urinary incontinence in postmenopausal women. 105 subjects were assessed between the age group of 45-65.

Results showed prevalence of $55 \%$ in the postmenopausal women. Comparing the results with population based studies, the prevalence of UI among women was higher than other studies among results of this study Senturk et al. reported prevalence of $45.6 \%$ in Turkey. ${ }^{7}$ Whereas Fred Kriss et al. reported prevalence of $18.12 \%$ in Estonian postmenopausal women, ${ }^{5}$ Townsend et al. reported prevalence of $14 \%$ in Mexican women ${ }^{9}$ and Sakondhavat et al. reported prevalence of $38.86 \%$ in khonkaen women ${ }^{14}$. This study showed prevalence of UI higher which can be due to lack of awareness of exercise in post natal period. And many people were illiterate and doesn't know the importance of exercise.

When percentage of urinary incontinence according to types of UI were distributed the proportions of SUI, UUI, MUI were found to be $22.41 \%, 32.75 \%$, $44.80 \%$, respectively. In accordance with this study Townsent et al. ${ }^{9}$ and Sakondhavat et al shows mixed postmenopausal group. In accordance with the 
was commonest type. ${ }^{14}$ While in contrast to this study Islam RM et al, ${ }^{8}$ Singh U et al, ${ }^{6}$ Fred Kriss et $\mathrm{al}^{5}$ and Zhu L et $\mathrm{al}^{13}$ reported Stress and Urge as the commonest type of UI.

In this study having BMI $25-29$ and $\geq 30 \mathrm{~kg} / \mathrm{m}^{2}$ tended to increase the risk of UI. In accordance with this study Islam RM et al. ${ }^{8}$, Townsen et al., ${ }^{9}$ Senturk et al. ${ }^{7}$, Fred Kriss et al. ${ }^{5}$, Zhu L et al. ${ }^{13}$, Ham E et al. $^{12}$, Brown JS et al. ${ }^{15}$, also reported that the potentially modifiable lifestyle factors such as overweight and obesity are associated with UI.

Significant association between UI and parity was found in this study which was also reported by Islam RM et al. in Bangladeshi women ${ }^{8}$, Townsend et al. in postmenopausal Mexican women, ${ }^{9}$ Singh U et al. in Indian women ${ }^{6}$,Senturk et al. in postmenopausal women living in Turkey, ${ }^{7} \mathrm{Zhu}$ L et al. in Beijing China, ${ }^{13}$ Ham $E$ et al in middle aged Korean women. ${ }^{12}$ Having parity $\geq 3$ increases the risk which was $64 \%$. The prevalence of UI in this study increased with age, it was found to be $45 \%$ in the age group of 45-55 and 55\% in the age group of 56-65. Which was also reported by Fred Kriss et al. ${ }^{5}$, Senturk et al. ${ }^{7}$, Zhu L et al. ${ }^{13}$, Brown JS et al. ${ }^{15}$.

Hysterectomy is considered as the starting point of pelvic floor symptoms, such as UI, constipation. This study in accordance with study conducted by Singh U et al. ${ }^{6}$, Fred Kriss et al. ${ }^{5}$, Ham E et al. ${ }^{12}$, Kudish BL et al. ${ }^{17}$, Brown JS et al. ${ }^{15}$, reports promotive effect of hysterectomy on UI. While in contrast to this study such effect was not found in prospective controlled studies conducted by Gustafsson C et al. ${ }^{18}$, Engh MA et al. ${ }^{19}$

Diabetes mellitus which is a metabolic disorder caused by an absolute or relative deficiency of insulin. A common complication of diabetes mellitus is diabetic bladder dysfunction which includes time dependent manifestation of storage and emptying problems, it may lead to UI.

It can be the risk factor for UI which is in accordance with the studies conducted by Townsend MK et al. in Mexican women ${ }^{9}$, Ham E et al. in middle aged Korean women ${ }^{12}$ and Danforth $\mathrm{KN}$ et al. $^{20}$ while no significant difference was found in a hospital bases survey done in Indian women ${ }^{8}$. In this study it was $50 \%$, but the number of women with diabetes was very low and thus we cannot make any conclusions.

\section{Conclusion}

The present study concluded that the prevalence of urinary incontinence among postmenopausal women was $55 \%$ at Talegaon Dabhade. The risk factors associated were parity 3 or more, high BMI, Diabetic Mellitus, Hysterectomy, Increasing age. Mixed urinary incontinence was the most common type.

\section{Scope and Limitation}

Scope: Further studies can be done with large sample size in which objective data can be taken by using pad test.

Limitation: Sample size was small and the results were not confirmed by doing pad test.

\section{Acknowledgement}

The authors would like to thank the staff of the MAEER's physiotherapy college, Talegaon Dabhade and also would like to thank subjects for their willingness to participate in the study.

\section{References}

1. Margret polden and Jill Mantle, first edition1990 reprint 2007, physiotherapy in obstetrics and gynecology, page no 346.

2. Pauline E Chiarelli, Lynette A Mackenzie, and Peter G Osmotherly. Urinary incontinence is associated with an increase in falls: a systematic review. Australian journal of physiotherapy.2009; 55:2; 89-95.

3. Ruth Sapsford Aua, Sue Markwell, Joanne Bullocks- saxton. Women Health: A textbook for physiotherapy.

4. Botlero R, Davis SR, Bell RJ, Urquhart DM. Prevalence and incidence of urinary incontinence in women: review of literature and investigation of methodological issues. International journal of urology.2008; 15:230-234. 
5. Fred Kirss, Katrin Lang, and PiretVeerus. Prevalence and risk factors of urinary incontinence among Estonian postmenopausal Women. Springer Plus 2013, 2: 524-531.

6. Singh U, Agarwal P, Verma ML, Dalela D. Prevalence and risk factors of urinary incontinence in Indian women: a hospital based survey. Indian journal of urology. 2013; 29 (1): 31-36.

7. Senturk S1, Kara M.Cross. Risk factors and prevalence of urinary incontinence in postmenopausal women living in Turkey. Clin Exp Obstet Gynecol.2012; 39 (1):6971.

8. Islam RM, Bell RJ, Davis SR, Hossain MB. Prevalence and risk factors: Types of Urinary incontinence in Bangladeshi women at midlife. Maturitas: An international journal of midlife health and beyond.2018:07; 012.

9. Townsend MK, Lajous M, Lopez-Ridaura R, Rice MS, Mary K, Raul Hernan MedinaCampos, Andres Catzin-Kuhlmann. Risk factors for urinary incontinence among postmenopausal Mexican women. International Urogynecology Journal.2017; 28(5):769-776.

10. Meral Killic. Incidence and risk factors of urinary incontinence in women visiting Family Health Centers. Springer plus.2016; 5 (1):1331.

11. Fiegan MM, Hanson JD, Benson KD, Prasek $\mathrm{J}$. The prevalence of urinary incontinence in Americam Indian women from a South Dakota tribe. International urogynecology journal.2012; 23(4):473-9.

12. Ham E, Choi H, Seo JT, Kim HG, Palmer MH, Kim I. Risk factors for female urinary incontinence among middle-aged Korean women. Journal of Women's Health.2009; 18(11):1801-6.

13. Zhu L, Lang J, Wang H, Haung J. The prevalence and potential risk factors for female urinary incontinence in Beijing, china. Menopause.2008; 15 (3):566-9.

14. Sakondhavat C, Choosuwan C, Kaewrudee S, Soontrapa S, Louanka K. The Prevalence and risk factors of urinary incontinence in khonkaen menopausal women. Journal Med Assoc Thai.2007; 90(12):2553-8.

15. Brown JS, Fong J, Ensrud KE, Seeley DG, Fong $\mathrm{J}$, and Black DM, Grady D. Urinary incontinence in older women: who is at risk? Study of Osteoporotic fractures research group. Obstet Gynecol.1996; 87(5 pt 1):71521.

16. Catherine S. Bradley MD, Eric S. Rovner MD, Mark A. Morgan MD, Michelle Berlin MD,Joseph M. Novi DO, Judy A. Shea PhD, Lily A.Arya MD.A new questionnaire for urinary incontinence diagnosis in women: Development and testing.(2005)192:166-73.

17. Kudish BL, Shieiky D, Gutman RE, Jacoby V, SokolAL,et al. Hysterectomy and urinary incontinence in postmenopausal women. International Urogynecology journal. 2014; 25(11):1523-31.

18. Gustafsson C, Ekstrom A, Brismar S, Altman D. Urinary incontinence after hysterectomy-three year observational study. Journal of Urology.2006; 68(4):769-74.

19. Engh MA, Lofgren M, Otterlind L Stjerndahl JH. Hysterectomy and incontinence: a study from Swedish national register for gynecological surgery. Obstetricia \& Gynaecology.2006; 85 (5):614-8.

20. Danforth KN, Townsend MK, Curhan GC, Renick NM, Grodstein F. Type 2 diabetes mellitus and risk of stress, urge, mixed urinary incontinence. The Journal of urology.2009; 181(1):193-197. 